\title{
An application of the HBV model to the Tamor Basin in Eastern Nepal
}

\author{
S. Normand ${ }^{1}$, M. Konz ${ }^{1} \&$ J. Merz ${ }^{2}$ \\ ${ }^{1}$ ETH Zurich, Institute of Environmental Engineering, Hydrology and Water Resources Management, \\ Wolfgang-Pauli-Str. 15, 8093 Zurich, Switzerland \\ Email:normands@student.etnz.ch \\ ${ }^{2}$ INTEGRATION environment \& energy, Kathmandu, Nepal
}

\begin{abstract}
The semi-distributed, conceptual hydrological model HBV was applied to Tamor Nadi in order to estimate runoff at Tapethok, Taplejung, in Eastern Nepal. As there was no discharge data available for this particular location, the model was first calibrated and validated for the bigger, gauged basins at Mulghat and Majithar. However due to its structure HBV shows difficulties in modelling low and high flows correctly at the same time. Therefore two parameter sets were produced: one with focus on the model performance during low flows and the second one, on high flows. Those parameters were then applied to the basin at Tapethok. Generally HBV was able to correctly simulate low flows except for some sharp peaks due to isolated precipitation events. However, pre-monsoon discharge was overestimated while the runoff of the monsoon season were most of the time underestimated. The main reasons for this situation are: (1) HBV generates runoff from one single groundwater reservoir for the entire catchment, leading to sharp peaks with a rapid recession and therefore exaggerated reactions on precipitation during dry season; (2) during pre-monsoon snow and ice melt gain in importance and add to the mentioned problem; (3) due to the simplified representation of storages in the model structure the catchment area drains too quickly.
\end{abstract}

\section{Keywords: Tamor Basin}

\section{INTRODUCTION}

Nepal is one of the world's richest countries with respect to hydropower potential (Shrestha, 1985). With an altitude range of nearly $8800 \mathrm{~m}$ the hydraulic gradient is enormous. The development of hydropower contributes to the development of the whole country. The Himalayan head watersheds and their glaciers are the sources of most of Nepal's rivers. Therefore, a reliable assessment of water resources in mountainous head watersheds is important for the development of hydropower potentials as well as for drinking water supply. To harvest Nepal's hydropower potential, homogeneous long term series of precipitation, temperature and discharge are necessary. Due to difficult access and harsh conditions of mountainous regions data gaps are frequent and therefore there is a great need of modelling procedures that can bridge these gaps. Konz et al. (2007) have shown that conceptual distributed or semi-distributed models are useful 
tools to simulate Himalayan headwaters. In this study we present an application of the conceptual HBV model to estimate discharge of the Tamor Nadi at Tapethok, Taplejung, in Eastern Nepal including necessary pre-processing steps to bridge gaps in the meteorological time series. Furthermore, we show how the semi-distributed model can be used to estimate discharge at points within the catchment but other than the gauging station that has been used for calibration. This regionalization is important for discharge estimates at potential but ungauged hydropower locations. In this study the discharge is estimated for the ungauged Tapethok site (Figure 1, marked with 0), a potential intake for a hydropower plant. We calibrated the HBV model to discharge observations further downstream and regionalized the parameters to get discharge predictions at the target location. The aim of this study is to demonstrate the entire modelling procedure and to provide assessments of the simulation results.

\section{STUDY SITE}

Tamor Nadi is located in Eastern Nepal and its basin shares borders with China and India. Figure 1 shows the basin's digital elevation model with the different measurement stations within the study basin and its vicinity. Two hydrological stations of the Department of Hydrology and Meteorology (DHM) are available for model calibration and validation: station 690 in Mulghat (276 m.a.s.l.) and station 684 in Majhitar (533 m.a.s.1.). DHM further observes precipitation and temperature at 11 precipitation and 7 temperature measurement stations, respectively. For the model only one meteorological station is needed (Taplejung, marked with the number 1405 in Figure 1), while the other ones serve for interpolation of missing data at that particular station. The target location for the discharge estimates, Tapethok, is marked with the number 0 .

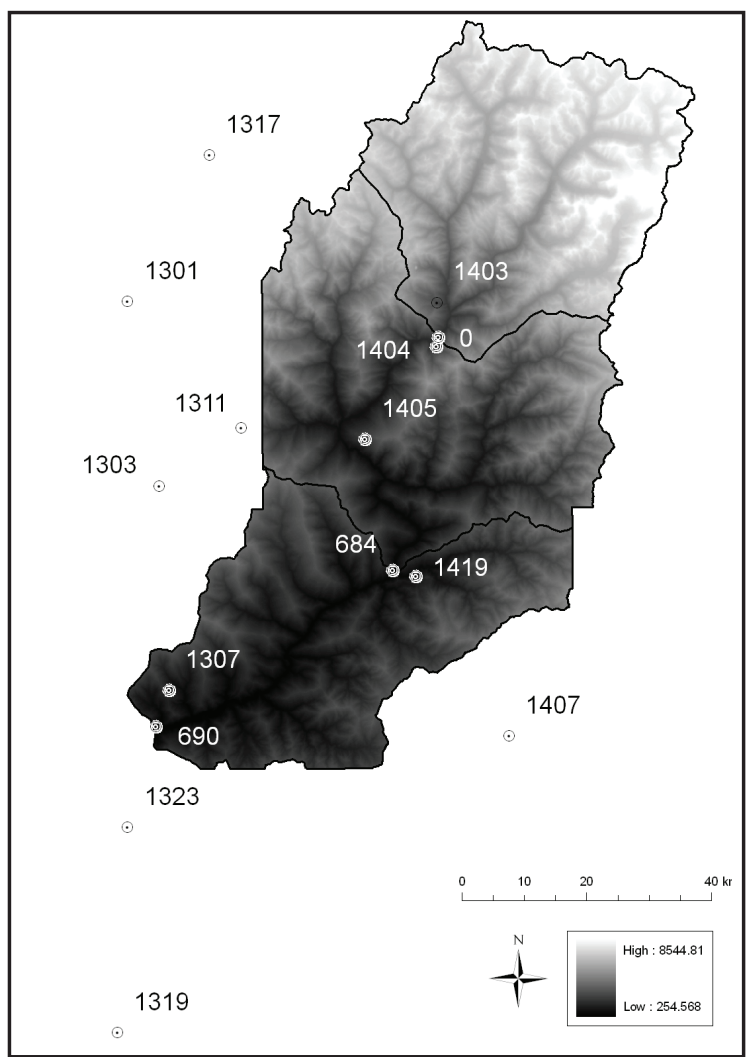

Figure 1: Study basin and available stations (data source: DHM and National Geographic Information Infrastructure Project (NGIIP), Survey Department)

\section{DATA AND METHODS}

For HBV application, temperature and precipitation measurements are required for one station representative for the basin and the station 1405 of Taplejung was used for this study. Temperature and precipitation data are regionalized to the catchment using gradients reflecting the changes of temperature and precipitation with elevation. In addition a digital elevation model is needed to extract altitude and exposition information. Glacier areas are required as the model differentiates between glacierized and non-glacierized parts of the catchment. Finally, measured discharge is required for calibration and validation of the model. 


\subsection{TEMPERATURE DATA}

At station 1405 only daily maximum and minimum temperatures are observed manually. The recommended method for calculating an average daily temperature from daily maximum and minimum values is to take the mean between them (World Meteorological Organisation, 2007). According to Valor et al. (2001), this is a reasonably good estimate compared to average daily temperatures based on the use of higherfrequency data.

Missing temperature data can be an issue for hydrological modelling. At station 1405 however, there are only 34 days without data between 1987 and 2006 , which corresponds to $0.47 \%$ of the time series. Those gaps are filled with extrapolated temperature data using a method based on annual data, which allows taking into account the specific synoptic situation of each year. Daily temperatures are therefore extrapolated from reference stations using a second order polynomial regression function, as it is recommended by Weber (1997) cited by Konz et al. (2006).

\subsection{PRECIPITATION DATA}

Problems that may arise while working with precipitation data are missing values and heterogeneities. The latter can be identified for example by a double mass analysis; in the case of station 1405 no heterogeneities could be found. Precipitation accumulation may also cause problems, but in our case no accumulated data were identified. Regarding missing data, there are 156 days without precipitation data at station 1405 between 1987 and 2006, which corresponds to $2.13 \%$ of the data range. The procedure of extrapolation of the missing daily sums of precipitation is a statistically based method (Konz et al., 2007). It uses data from reference stations, which are weighted according to (1) the mean ratio of the monthly precipitation between station 1405 and reference station; and (2) the joint occurrence probability of precipitation at both stations for one month.

\subsection{DISCHARGE}

The measured discharges in Majhitar and Mulghat are given in $\mathrm{m}^{3} / \mathrm{s}$ as mean daily value. Some inconsistencies in the recorded discharge data were found especially during low flows, where the discharge curve was suddenly shifted by several $\mathrm{m}^{3} / \mathrm{s}$. There were data gaps or sudden peaks without physical meaning (according to the meteorological data at disposal and comparisons with the model results). Direct comparison of discharge data at the two hydrological stations revealed that sometimes recorded values in Majhitar were higher than in Mulghat, which makes no sense because Majhitar is located upstream of Mulghat. Inconsistent data were not used during model results analysis, for which only sound data were considered.

\subsection{TOPOGRAPHIC DATA}

The digital elevation model was generated with ArcGIS on the basis of contour lines of the digital topographic maps,by the Survey Department, Ministry of Land Reform and Management of the Government of Nepal in cooperation with the government of Finland. A $50 \mathrm{~m}$ x $50 \mathrm{~m}$ digital elevation model was generated, from which the information necessary to the model application was derived. Basin areas and characteristics are given in Tables 1 and 2.

Table 1: Basin areas

\begin{tabular}{lc}
\hline \multicolumn{1}{c}{ Basin outlet } & Basin area $\left(\mathbf{k m}^{2}\right)$ \\
\hline Mulghat & 5763.0 \\
Majhitar & 3918.3 \\
Tapethok & 1819.4 \\
\hline
\end{tabular}


Table 2: Basins characteristic

\begin{tabular}{lcc}
\hline Basin outlet & $\begin{array}{c}\text { Non glacier- } \\
\text { ized area (\%) }\end{array}$ & $\begin{array}{c}\text { Glacierized } \\
\text { area (\%) }\end{array}$ \\
\hline Mulghat & $94.46 \%$ & $5.54 \%$ \\
Majhitar & $91.85 \%$ & $8.16 \%$ \\
Tapethok & $82.60 \%$ & $17.41 \%$ \\
\hline
\end{tabular}

\section{THE HBV MODEL}

\subsection{MODEL DESCRIPTION}

In HBV basins can be discretized in up to 20 userdefined altitude belts, each one subdivided into three orientation classes (North, South, East-West). Additionally this version of the model differentiates between glacierized and non-glacierized areas. HBV consists of the snow, soil and runoff generation routines, whereas the latter is based on linear storage concepts (Figure 2). The routines are applied to each HBV class to generate the runoff at the outlet of the basin (for more details about HBV, refer to Konz et al. (2006) and Seibert (2005)).

SNOW AND GLACIER ROUTINE-HBV applies a temperature-index method (degree-day method) to calculate snow and ice melt, depending on exposition and form of the snowpack. The inputs are daily air temperature and precipitation, which are both adapted to the elevation of the altitude belt using correction factors. HBV differentiates between liquid and solid precipitation based on a threshold temperature, whereas the latter is corrected to account for systematic errors. Finally storage and refreezing of liquid water in the snow cover are estimated. Water is stored in solid form in the snowpack and in liquid form inside the snow cover, so when the water retention capacity is reached, additional water enters the soil routine.

SOIL ROUTINE - In this routine HBV calculates soil moisture storage, infiltration and percolation through the soil as well as actual evapotranspiration. Rainfall and snowmelt are directed partly to the soil moisture storage and partly to the groundwater zone. Infiltrated water leaves the soil routine and goes into the runoff generation routine.

RUNOFF GENERATION ROUTINE - There is one single groundwater storage for the entire basin, which is the basis of the runoff generation routine. Groundwater recharge from the soil routine is directed to an upper groundwater box, from which water can further percolate to a lower box as long as the maximum percolation rate is not reached. Runoff from those two boxes is computed as the sum of two linear reservoir response functions and finally transformed by a triangular weighting function to obtain the simulated discharge.

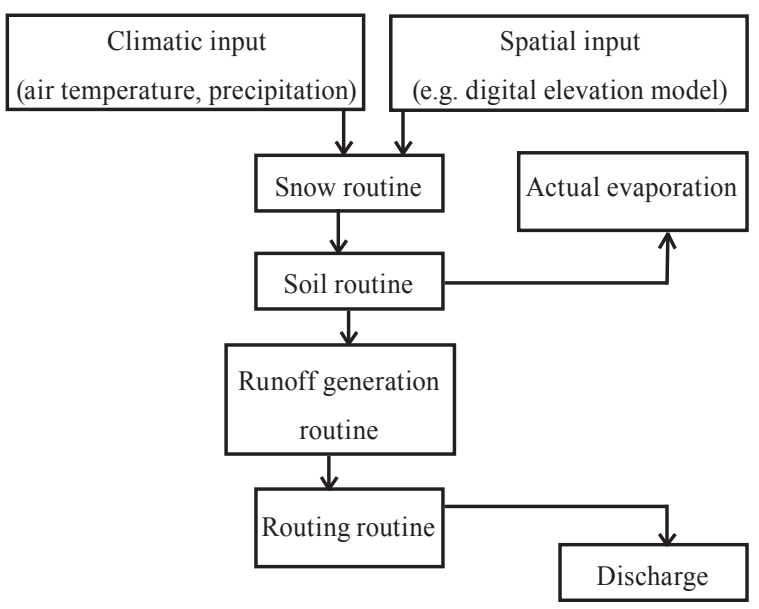

Figure 2: Structure of the HBV model (Konz et al. (2006))

\subsection{MODEL CALIBRATION}

HBV was calibrated on the time period from 01/01/1987 to $31 / 12 / 1996$ with the discharge data recorded in Mulghat. Firstly automatic Genetic Algorithm Package (GAP) optimization was applied and then manual calibration was done to refine the parameters by “trial and error". In addition 
to the visual inspection of the simulated time series with the observed ones, several objective criteria were used to assess the best parameter set: NashSutcliffe efficiency, logarithmic model efficiency (emphasizes the weighting of low discharges), coefficient of determination, volume error and peak efficiency (Nash-Sutcliffe efficiency calculated only with peak values). The application of HBV to the available data set for the Tamor River does not allow obtaining good low and high flows data with the same parameter set. This is due to the models relatively simple, conceptual structure with one single groundwater storage responsible for the runoff generation. Therefore two different parameter sets were produced during manual calibration with one focusing on low flows and the other one on high flows. Calibration results are shown in Table 3 with the values of the water balance and of the different objective criteria (results obtained with the parameters from the
GAP optimization are also shown for comparison). Figure 2 shows one typical example of the simulated and observed runoffs.

Table 3: Calibration results as calculated by HBV (bold figures show the best results)

\begin{tabular}{lccc}
\hline & $\begin{array}{c}\text { GAP opti- } \\
\text { mization }\end{array}$ & $\begin{array}{c}\text { Focus on } \\
\text { low flows }\end{array}$ & $\begin{array}{c}\text { Focus on } \\
\text { high flows }\end{array}$ \\
\hline Water balance 1987-1996 (mm/year) & & \\
\hline $\begin{array}{l}\text { Sum of } Q_{\text {sim }} \\
\text { Sum of } Q_{\text {obs }}\end{array}$ & 1980 & 1816 & 2090 \\
$\begin{array}{l}\text { Sum of } \\
\text { precipitation }\end{array}$ & 1927 & 1927 & 1927 \\
\hline Objective criteria & 2019 & 2019 & 2019 \\
\hline $\mathrm{R}^{2}(-)$ & 0.693 & 0.689 & 0.649 \\
$\mathrm{R}_{\text {eff }}(-)$ & 0.692 & 0.680 & 0.622 \\
$\mathrm{R}_{\text {log,eff }}(-)$ & 0.858 & 0.870 & 0.749 \\
VE (mm/year) & -52 & 111 & -162 \\
Peaks efficiency & 0.500 & 0.461 & 0.613 \\
\hline
\end{tabular}

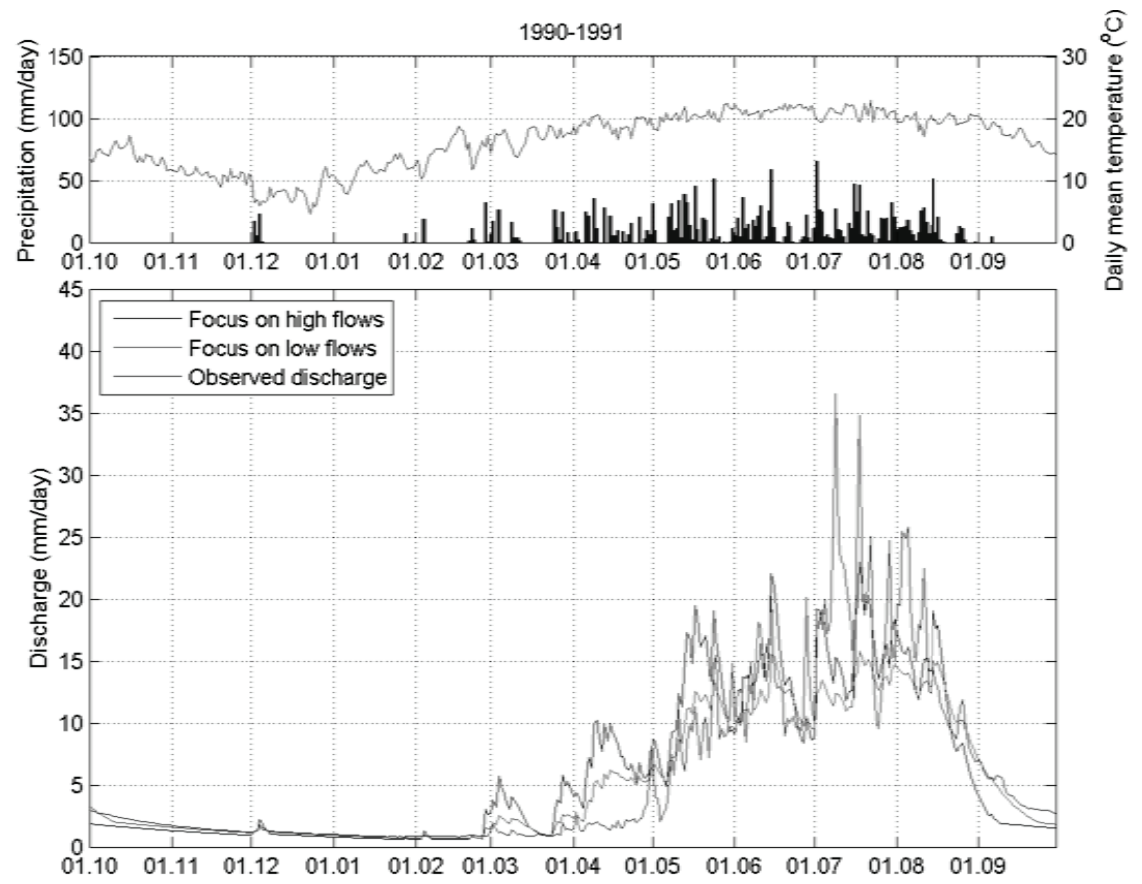

Figure 3: Simulation results for hydrological year 1990-1991 
Generally the timing of the simulated peaks corresponds to the observed ones. During low flows (November - April) the simulated discharge usually fits the measured one quite well, except for the reaction on precipitation events. When rain falls during the dry season, it results in a high and sharp peak of the modelled runoff, while in reality the discharge curve remains much flatter. In the pre-monsoon time (May June) the simulated curves are much too high with sharp peaks showing a quick response of the basin on the precipitation event. During the monsoon season (July - October) the baselines and the peaks of the simulated discharges are both too low. Also the calibration focusing on high flows does produce satisfactory results: this parameter set allows for better catching of the peaks, but after this the baseline falls too low. The volume error is in general quite high. Actually this criterion was not much regarded because of the split calibration process (low versus high flows) which suggests that we cannot model the entire year properly. Therefore volume error should be calculated only over high or low flow periods to make more sense.

\subsection{MODEL VALIDATION}

Validation was done with the parameter sets with focus on high flows and focus on low flows, as well as with the parameter set from the GAP optimization for comparison. First the model was validated for the Mulghat basin from 01/01/1997 to 31/12/2006 and afterwards for the Majhitar basin from 01/01/1996 to $31 / 12 / 2005$ with the same parameter sets. Finally the model was applied to the Tapethok basin. As there are no discharge measurements in Tapethok a reduction factor according to the basin area was applied to the observations in Majhitar. Discharge values for March were compared with one single discharge measurement with ADCP instrument (Merz, 2009) made in March 2009, where the observed runoff was around $15 \mathrm{~m} 3 / \mathrm{s}$ in Tapethok. Extrapolated values range from ca. 12 to $30 \mathrm{~m} 3 / \mathrm{s}$, with the majority of the data higher than $20 \mathrm{~m} 3 / \mathrm{s}$. Extrapolated low flow values seem to be therefore consistent with the measurement, but it is a very rough approximation and more data would be needed to validate the extrapolation. Figures 3, 4 and 5 show the validation results for the three basins for the hydrological year 2001-2002.

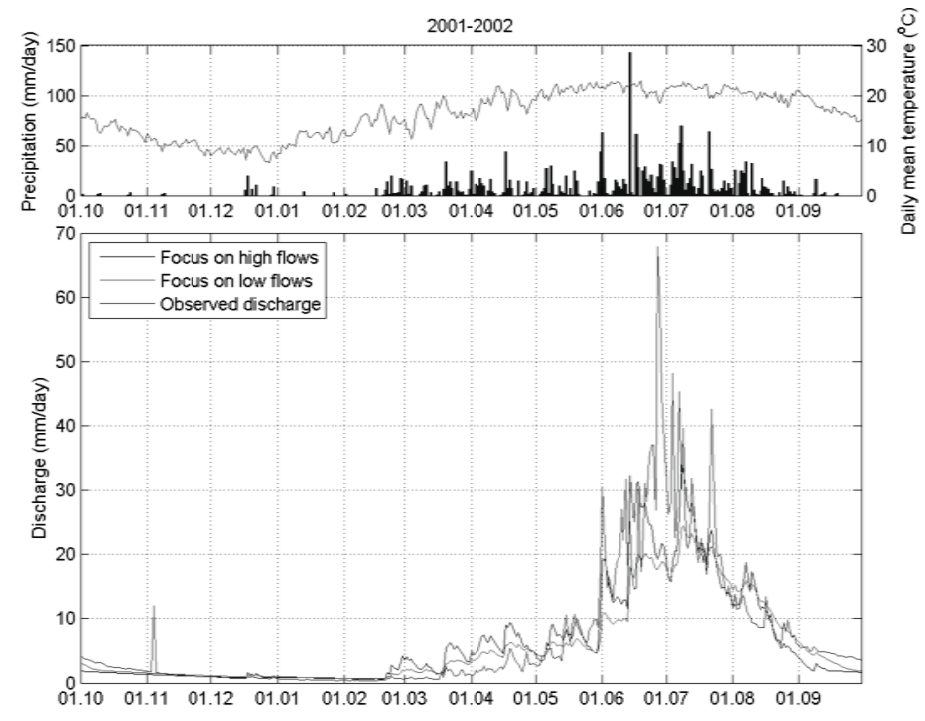

Figure 4: Validation results in Mulghat for the hydrological year 2001-2002 


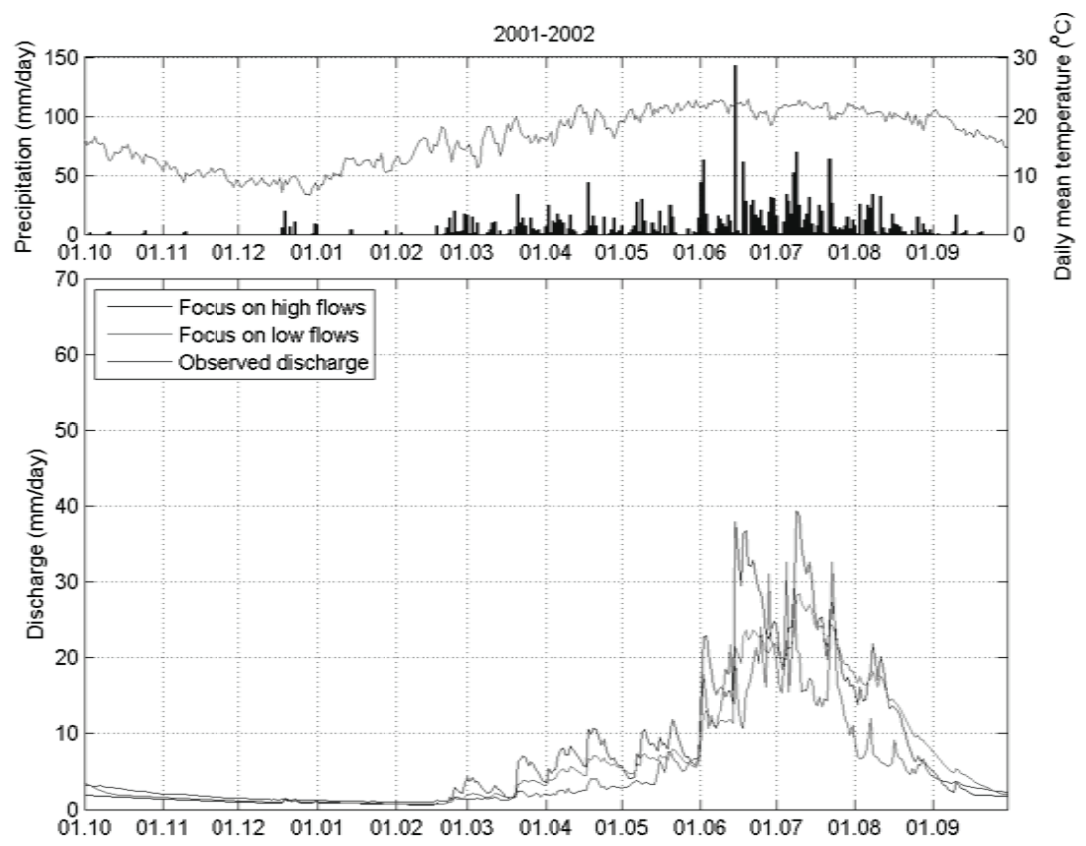

Figure 5: Validation results in Majhitar for the hydrological year 2001-2002
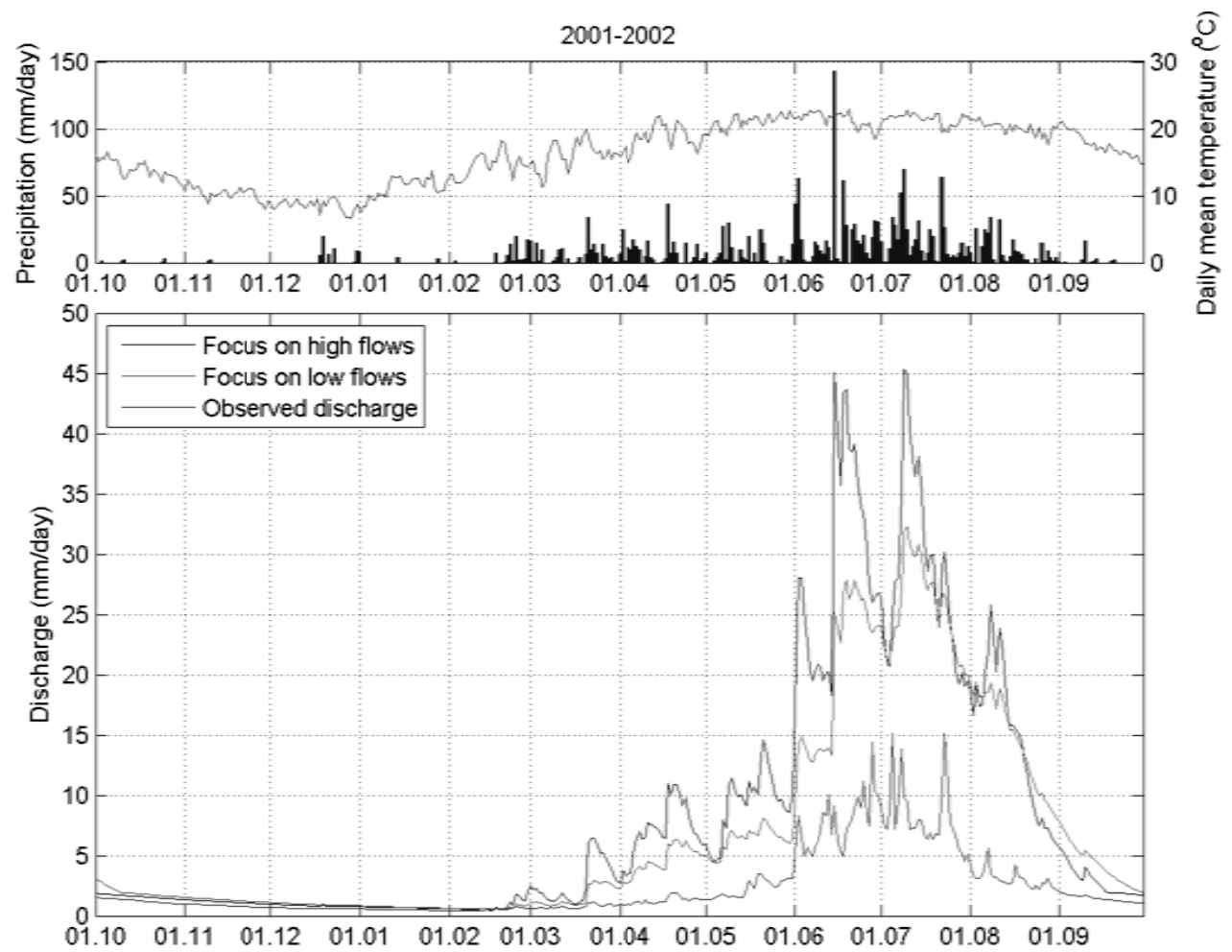

Figure 6: Validation results in Tapethok for the hydrological year 2001-2002 
The shape of the discharge curves in Mulghat is similar to the one obtained during the calibration process. Also in Majhitar the situation is the same, even if the high flow season seems to be slightly better modelled than in Mulghat. Finally in Tapethok the simulated discharge is too high all around the year, especially during pre-monsoon and monsoon with sharp, high peaks. However it is difficult to get an objective evaluation of those results as there are no measurements there and "observed" discharge values were actually extrapolated. The discharge values given in Table 4 hereafter must therefore be considered as rough estimations.

Table 4: Simulated discharge in Tapethok. Mean monthly values are computed over a period of $\mathbf{1 0}$ years (1996-2005). $Q_{\text {low }}$ shows the results with the parameter set focusing on low flows, $Q_{\text {high }}$ with the parameter set focusing on high flows.

\begin{tabular}{llcc}
\hline & & $\mathbf{Q}_{\text {low }}\left(\mathbf{m}^{3} / \mathbf{s}\right)$ & $\mathbf{Q}_{\text {high }}\left(\mathbf{m}^{3} / \mathbf{s}\right)$ \\
\hline Mean & January & 18.6 & 16.9 \\
Monthly & February & 14.0 & 13.2 \\
Discharge & March & 12.7 & 14.5 \\
& April & 28.1 & 54.0 \\
& May & 88.9 & 156.1 \\
& June & 192.6 & 292.1 \\
& July & 336.6 & 457.1 \\
& August & 366.3 & 448.1 \\
& September & 251.2 & 282.2 \\
& October & 117.2 & 106.2 \\
& November & 38.3 & 32.7 \\
& December & 26.3 & 23.6 \\
\hline Maximum daily value & 680.3 & 969.9 \\
Minimum daily value & 9.3 & 9.6 \\
\hline
\end{tabular}

\section{DISCUSSION}

Simulation of the baseflow is relatively good in Mulghat and Majhitar. During winter, runoff is generated mainly from groundwater, with additional contribution of snow and ice melt on warmer days. The exaggerated reaction of the simulated runoff to the few rainfall events may have different reasons: Possibly the input precipitation data are less representative of the situation in the dry season. In winter precipitation events are spatially more limited. Therefore applying a single observation may be a too rough assumption for such a big study area. The peaks are not only too high, but also very sharp. It may be a sign for a too rapid response of the model, due to the fact that HBV generates runoff from one single groundwater reservoir for the entire catchment. In the premonsoon snow and ice melt gain in importance and add to the problems that already existed for precipitation events during low flows. Sharp peaks and rapid recession after precipitation events in the monsoon season are a typical storage problems, due to the limited possibilities of adequate simulation with only one storage for the entire basin. The catchment area drains too quickly. Possibly the different storages (snow, soil, groundwater) were dimensioned too small. In the smaller ungauged Tapethok catchment the basin characteristics are different from Mulghat, with a much higher percentage of glacierized areas and areas on high altitudes. Therefore some errors that may result from the calibration in Mulghat are emphasized in Tapethok. This argumentation can also be supported by the fact that peaks are underestimated in Mulghat, better caught in Majhitar and finally overestimated in Tapethok. It seems that the parameter set resulting from the calibration in Mulghat cannot just be applied to the smaller basins. Efficiency for different periods vary a lot. Sometimes the efficiency is even negative. This is partly due to missing discharge observations or inconsistent measurements. Here the modelling results provide good information to assess the observations. 


\section{CONCLUSION}

Application of HBV model to the Tamor basin resulted in a good simulation of low flows. However, pre-monsoon and monsoon periods exhibit short comings in the model performance. The HBV model is a conceptual model with a semi distributed spatial resolution. This is efficient in terms of computation time and enables a detailed parameter study; however spatial information and water storage distributions cannot be considered. The simulated runoff data at Tapethok are therefore considered to be reliable for low flows. Peak flow simulations require additional efforts and more complex models should be tested in order to improve discharge simulations. To obtain more reliable results, application of a distributed model to the study area is recommended and will be done in a follow up study. Internal model consistency can be checked and improved by multi-criteria calibration, which strongly enhances the model results. Remotely sensed data like MODIS snow cover products can be used to calibrate the models in data scarce regions (Konz et al., 2010 submitted to IAHS). Moreover gathering of additional hydrological and meteorological data in the basin would support the process of ameliorating the simulation results.

\section{ACKNOWLEDGEMENT}

The authors would like to thank Sanima Hydropower Pvt. Ltd. for financial support for this study and for providing the necessary input data.

\section{REFERENCES}

Google Earth Version 5.1.3509.4636 (beta)

Konz et al., 2006: Runoff from Nepalese Headwater Catchments - Measurements and Modelling. IHP/HWRP - Berichte.
Konz, M., Braun, L., Uhlenbrook, S., Shrestha, A., Demuth, S.: Implementation of a processbased catchment model in a poorly gauged, highly glacierized Himalayan headwater, Hydrol. Earth Syst. Sci., 11, 1323-1339, 2007.

Konz, M.; Finger, D.; Bürgi, C.; Normand, S.; Immerzeel, W.W. ; Merz, J. ; Amarnath, G. ; Burlando, P., 2010: Calibration of a distributed hydrological model for simulations of remote glacierized Himalayan catchments using MODIS snow covers data. Submitted as conference proceeding of IAHS world FRIEND conference 2010, Morocco.

Konz, M. \& Seibert, J., 2010: On the value of glacier mass balances for hydrological model calibration. Journal of Hydrology.

Merz, J., March 2009: Discharge measurements with a StreamPro ADCP - Upper Tamor Hydropower Project. ADCP Report 001/09.

Normand, S., December 2009: Hydrological Study of the Tamor Basin - Field Trip Report for November 2009. Report 006/09.

Seibert, J., 2005: HBV light version 2, User's Manual.StockholmUniversity, Department of Physical Geography and Quaternary Geology.

Seibert, J., 1999: Regionalisation of parameters for a conceptual rainfall-runoff model. Agricultural and Forest Meteorology 98-99, pp. 279-293.

Seibert, J. \& Beven, K. J., 2009: Gauging the ungauged basin: how many discharge 
measurements are needed? Hydrology and Earth System Sciences, 13, 883 - 892.

Shrestha, H.M., 1985: Water Power Potential. In Majupuria, T.C. (ed.) Nepal-Nature's Paradise, pp 32-38. Bangkok: White Lotus.
Valor E., Meneu V., Caselles V., 2001. Daily Air Temperature and Electricity Load in Spain. American Meteorological Society, 1413 1421.

World Meteorological Organisation, 3 May 2007. Guide to Climatological Practices, draft 3rd edition, pp. 117. 